\title{
The effects of an interpersonal relationship improvement program on self- esteem, interpersonal orientation, and ego-resilience on Korean adolescents.
}

\author{
Young Ran Yeun', Hee Young Woo ${ }^{2 *}$ \\ ${ }^{1}$ Department of Nursing, Kangwon National University, 346 Hwangjogil, Dogyeeup, Samcheok, Gangwondo, Republic \\ of Korea \\ ${ }^{2}$ Department of Nursing, Sahmyook Health University, 82 Manguro, Dongdaemun-gu Seoul, Republic of Korea
}

\begin{abstract}
The purpose of this study was to investigate the effects of an interpersonal relationship improvement program on self-esteem, interpersonal orientation, and ego-resilience on Korean adolescents. In this randomized controlled trial (RCT), 62 eligible participants were randomly assigned to either group A (intervention, $n=30$ ) or group $B$ (usual care, $n=32$ ). Self-esteem, interpersonal orientation, and egoresilience were measured at the baseline, and a three-week follow-up was conducted. The t-test was then used to determine the effect of intervention. The mean self-esteem $(p=0.002)$, interpersonal orientation $(p=0.000)$, and ego-resilience $(p=0.000)$ significantly increased after intervention. Thus, the results of this study suggested that the interpersonal relationship improvement program could be utilized as an effective means to improve mental and social health of adolescents.
\end{abstract}

Keywords: Relationship, Self-esteem, Interpersonal orientation, Ego-resilience, Adolescents.

Accepted on November 15, 2018

\section{Introduction}

Interpersonal skills, which are acquired especially during adolescence, are the basis of the quality of life and type of social adaptation in adulthood [1]. However, Korean adolescents are experiencing many difficulties in interpersonal relations. According to the report of the Korea Youth Counseling and Welfare Institute, the difficulty caused by an interpersonal relationship was ranked second $(24.9 \%)$ in youth counseling problems [2].

An interpersonal relationship can significantly influence the psychological health of adolescents. When a satisfactory interpersonal relationship is formed, self-identity is established, a healthy personality develops, and the levels of selffulfillment and happiness increase [3]. However, if the interpersonal relationship needs are not met, youths can experience psychological problems, such as depression, anxiety, and loneliness, and behavioral problems, such as school maladjustment, antisocial behaviors, aggressive behaviors, social phobia, and delinquency [4]. Therefore, it is highly important to develop a program that can help adolescents, who are in the process of forming their personalities, accept themselves and their peers, and promote healthy interpersonal relationships.

Therefore, this study aims to identify the effects of the interpersonal relationship improvement program (IRIP) on the self-esteem, interpersonal orientation, and ego-resilience of adolescents, and to pave the way for the establishment of healthy interpersonal relations for adolescents.

\section{Materials and Methods}

Adolescents aged 13-17 y were randomly assigned to group A (intervention, $\mathrm{n}=30$ ) or $\mathrm{B}$ (usual care, $\mathrm{n}=32$ ) using Research Randomizer computer software. The mean age of the subjects was $14.5 \mathrm{y}$, consisting of 14 males and 48 females. The results of the homogeneity analysis showed no significant difference between groups A and B. This study adhered to the Helsinki Declaration, and written informed consent was obtained from each participant.

The IRIP was developed based on the previous study and the youth program conducted by the Youth Relations Research Center at S university [5]. For group A, a total of six IRIP sessions were given, consisting of $60 \mathrm{~min}$ per session and 2 sessions per week. All sessions were composed of individual activities and group activities to enhance educational effectiveness. The 1 st session comprised of the orientation time in which the program was explained, goals were set, and participants introduced themselves. In the $2^{\text {nd }}$ and $3^{\text {rd }}$ sessions, activities for self-disclosure and understanding other people were held. In the $4^{\text {th }}$ and $5^{\text {th }}$ sessions, participants acquired skills in communication and relationship building. In the $6^{\text {th }}$ session, participants shared their future plans and overall impressions. 
Self-esteem, Interpersonal orientation and Ego-resilience were measured by using the Self Perception Profile for children [6], interpersonal relations scale [7] and ego-resiliency scale [8].

All of the data were expressed as means \pm standard deviations. The homogeneity of groups A and B was analysed using t or Chi-square tests. The effects of the intervention on self-esteem, interpersonal orientation and ego-resilience were analysed using t-tests. Data analysis was performed using SPSS Statistics for Windows version 20.0 (IBM Corp., Armonk, USA). The significant level was set at $\mathrm{p}<0.05$.

\section{Results}

The results showed significant improvements in self-esteem, interpersonal orientation and ego-resilience subsequent to the intervention (Table 1).

Table 1. Clinical outcomes of baseline and follow-up examination in groups $A$ and $B$.

\begin{tabular}{|c|c|c|c|c|c|c|c|c|}
\hline \multirow[t]{2}{*}{ Variable } & \multirow[t]{2}{*}{ Group } & \multicolumn{4}{|c|}{ Examination } & \multicolumn{2}{|l|}{ Changes } & \multirow[t]{2}{*}{$\mathbf{p}$} \\
\hline & & Baseline & & Follow u & & & & \\
\hline \multirow[t]{2}{*}{ Self-esteem } & A & $\begin{array}{l}86.10 \\
12.82\end{array}$ & \pm & $\begin{array}{l}94.13 \\
10.02\end{array}$ & \pm & $\begin{array}{l}8.03 \\
6.21\end{array}$ & \pm & 0.002 \\
\hline & B & $\begin{array}{l}87.91 \\
12.16\end{array}$ & \pm & $\begin{array}{l}85.81 \\
10.41\end{array}$ & \pm & $\begin{array}{l}-2.10 \\
1.57\end{array}$ & \pm & \\
\hline \multirow[t]{2}{*}{$\begin{array}{l}\text { Interpersonal } \\
\text { orientation }\end{array}$} & $A$ & $\begin{array}{l}50.50 \\
7.62\end{array}$ & \pm & $\begin{array}{l}55.17 \\
7.38\end{array}$ & \pm & $\begin{array}{l}4.67 \\
5.86\end{array}$ & \pm & 0 \\
\hline & B & $\begin{array}{l}49.22 \\
5.27\end{array}$ & \pm & $\begin{array}{l}48.34 \\
5.35\end{array}$ & \pm & $\begin{array}{l}-0.88 \\
2.39\end{array}$ & \pm & \\
\hline \multirow[t]{2}{*}{ Ego-resilience } & $A$ & $\begin{array}{l}36.97 \\
6.91\end{array}$ & \pm & $\begin{array}{l}40.20 \\
6.52\end{array}$ & \pm & $\begin{array}{l}3.23 \\
2.55\end{array}$ & \pm & 0 \\
\hline & $\mathrm{B}$ & $\begin{array}{l}34.13 \\
4.36\end{array}$ & \pm & $\begin{array}{l}34.25 \\
4.75\end{array}$ & \pm & $\begin{array}{l}0.12 \\
2.38\end{array}$ & \pm & \\
\hline
\end{tabular}

\section{Discussion}

The results showed that the IRIP was effective in improving the Korean adolescents' self-esteem and interpersonal orientation. Bang et al. [9] reported that the adventure-based counseling program was effective in improving the adolescents' self-esteem and interpersonal relationships. The study of Gao et al. [10] showed that the social skill group counseling program was effective in improving the self-esteem of children. These findings can be interpreted as the IRIP helped adolescents develop their concepts of self positively via self-objectification, in which they found their merits and examined their own values. Furthermore, the group activity in the program seems to have promoted interpersonal orientation by improving communication skills, which are helpful in building relationships after accepting other people with a positive attitude [11]. Therefore, it is important to develop a program that can acquire the respect for each other, values, and interpersonal conflicts in relation to peers.

Another important finding was the discovery that IRIP was effective in improving ego-resilience. A previous study demonstrated that a transactional analysis group program increased the resilience of adolescents [12]. Similarly, an RCT showed that their ego-resilience significantly improved after attending a personality education program [13]. According to Kim [14], activities with peers improve the ability to mobilize flexible behaviors and problem-solving methods, which are suitable in enhancing one's sense of community, self-esteem, and situational needs. Thus, the IRIP might improve egoresilience by improving the adolescents' positive awareness to help them cope with different situations, and to adopt more coping strategies.

\section{References}

1. Park YS, Kim UC. The quality of Life and interpersonal relationships among Korean adolescents. KJEP 2008; 22: 801-836.

2. Korea Youth Counselling and Welfare Institute. Consultation trend analysis report 2012.

3. Kiviruusu O, Berg N, Huurre T, Aro H, Marttunen M, Haukkala A. Interpersonal conflicts and development of self-esteem from adolescence to mid-adulthood. A 26year follow-up. PLoS One 2016; 11: 0164942.

4. Huprich SK, Lengu K, Evich C. Interpersonal problems and their relationship to depression, self-esteem, and malignant self-regard. J Pers Disord 2016; 30: 742-761.

5. Jeon MS, Kwon IN. A study on the development of youth interpersonal relationship competency program. Korean J Youth Studies 2012; 19: 149-177.

6. Harter S. The self-perception profile for children: revision of the perceived competence scale for children. Univ Denver 1985.

7. Kim CH. Relationship between on body image, selfesteem and interpersonal relations according to golf of youth. KJS 2010; 8: 17-27.

8. Block JH, Block J. The role of ego-control and egoresiliency in the organization of behavior. Minn Symp Child Psycho 1980. 13: 39-101.

9. Bang SH, Bang ER. An adventure-based counseling program development on self-esteem and interpersonal relationship for polytechnic school students. J Youth Welfare 2009; 11: 73-100.

10. Gao H, Hwang MH, Kang YI. The development of social skill group counseling program for ethnic minority children. KJYC 2010; 18: 71-84.

11. Gorrese A, Ruggieri R. Peer attachment and self-esteem: a meta-analytic review. Pers Individ Dif 2013; 55: 559-568.

12. Lee YH, Kim SH. A study on effect of transactional analysis group program on resilience of the children care facilities. J School Soc Work 2014; 27: 109-136.

13. Kim JY, Gwack NE. The effects of personality education program using the virtues on childrens ego-resilience and peer relationship in elementary school. KJCM 2016; 15: 99-125.

14. Kim JH. The effects of youth volunteering on community consciousness and Life satisfaction mediated by self- 
The effects of an interpersonal relationship improvement program on self-esteem, interpersonal orientation, and egoresilience on Korean adolescents

esteem and ego-resilience. J Youth Welfare 2012; 14:

$41-62$.

\section{*Correspondence to}

Hee Young Woo

Department of Nursing

Sahmyook Health University

Republic of Korea 